\title{
dspace.vutbr.cz
}

\section{Droplet dynamics and size characterization of high-velocity airblast atomization}

URBÁN, A.; ZAREMBA, M.; MALÝ, M.; JOZSA, V.; JEDELSKÝ, J.

International Journal of Multiphase Flow

2017, vol. 95, October 2017, pp. 1-11

ISSN: 0301-9322

DOl: https://doi.org/10.1016/j.ijmultiphaseflow.2017.02.001

Accepted manuscript

(C) 2012. This manuscript version is made available under the CC-BY-NC-ND 4.0 license (http://creativecommons.org/licenses/by-nc-nd/4.0/), doi:

https://doi.org/10.1016/j.ijmultiphaseflow.2017.02.001

Final version available from https://www.sciencedirect.com/science/article/pii/s0301932216303093 


\section{Highlights}

The spray from an airblast atomizer was investigated by the Phase-Doppler technique. The drop size-velocity data determined the properties of the gas and droplet phases.

Formulae to estimate mean diameters and size distributions of sprays were evaluated. The Gamma PDF described most accurately the size distribution of the spray. 


\title{
Droplet dynamics and size characterization of high-velocity airblast
}

\section{atomization}

András Urbán ${ }^{\mathrm{a}}$, Matouš Zaremba ${ }^{\mathrm{b}}$, Milan Malýb, Viktor Józsa ${ }^{\mathrm{a} 1}$, Jan Jedelskýb

a Department of Energy Engineering, Budapest, University of Technology and Economics, 1111 Budapest, Mủegyetem rkp. 3., Hungary

${ }^{\mathrm{b}}$ Faculty of Mechanical Engineering, Brno University of Technology, Technicka 2896/2, 61669 Brno, Czech Republic

\begin{abstract}
Airblast atomizers are especially useful and commonplace in liquid fuel combustion applications. However, the spray formation processes, the droplet dynamics and the final drop size distributions are still not sufficiently understood due to the coupled gas-liquid interactions and turbulence generation. Therefore, empirical and semi-empirical approaches are typically used to estimate the global spray parameters. To develop a physical understanding of the spray evolution, a plain-jet airblast atomizer was investigated in an atmospheric spray rig using the Phase-Doppler technique. The simultaneous drop size and axial and radial velocity components were measured on radial traverses across the spray at various axial distances from the nozzle for a range of atomizing pressures. The droplet turbulent and mean kinetic energies were found to be proportional to the atomizing pressure. Hence, the scatter of the radial motion of the droplets increased with the atomizing pressure. A droplet stability analysis was performed to locate the regions characterized by ongoing secondary atomization. The volume-tosurface diameter, $D_{32}$, of the fully developed spray was compared with estimates provided by five published formulae. The role of liquid viscosity, hence the Ohnesorge number, was found to be negligible in the investigated regime. Three commonly used size distribution functions were fitted to the measured data to analyze their dependence on the atomizing pressure. The Gamma distribution function was found to give the best approximation to the atomization process.
\end{abstract}

Keywords: plain-jet airblast atomizer, droplet size distribution, liquid breakup, PhaseDoppler Anemometry, Sauter mean diameter, spray stability

\footnotetext{
${ }^{1}$ Corresponding author. Tel.: +3614632596

E-mail addresses: u.andras07@gmail.com (András Urbán), zaremba@fme.vutbr.cz (Matouš Zaremba), milanmaly@email.com (Milan Malý), jozsa@energia.bme.hu (Viktor Józsa), Jan Jedelský (jedelsky@fme.vutbr.cz)
} 


\section{Introduction}

Airblast atomization is a widely used method for disintegrating liquids into droplets in, e.g., metallurgy, coating, painting technologies, and liquid fuel combustion. The aim of the atomization process is to create small enough fractions of the liquid, in combustion applications, it is a crucial process which significantly affects the pollutant emission, ignition characteristics, flame stability, and combustion efficiency (Correa, 1993; Lefebvre and Ballal, 2010). The smallest droplets evaporate fast and facilitate ignition while the largest ones increase the pollutant emissions (Babinsky and Sojka, 2002; Lefebvre, 1989). Consequently, not only is a mean droplet size of primary importance, but the size distribution functions are necessary for certain applications.

Airblast atomization was systematically analyzed first by Nukiyama and Tanasawa in 1939. Numerous studies investigated spray characterization since then (Bolszo, 2005; Gupta et al., 2010; Prussi et al., 2012), especially to understand the physical background of droplet formation which is essential for practical applications (Lasheras et al., 1998; Varga et al., 2003). Even though there are several works analyzing the droplet dynamics in sprays generated by the twin-fluid atomizers, (e.g., Ikeda et al., 1997; Jedelsky and Jicha, 2013; Kourmatzis and Masri, 2014), the atomization process is still not fully understood. Currently, the plain-jet airblast atomizer of a Capstone C-30 micro gas turbine burner is investigated which was analyzed by other researchers (Bolszo, 2005; Nakamura et al., 2008; Prussi et al., 2012) due to its simple geometry and operation. In order to track the liquid breakup and the droplet dynamics, the analysis based on the Stokes number is often used to process experimental data, see, e.g., (Santolaya et al., 2010). The ambient flow field is often traced using artificial small seeding particles (Breña de la Rosa et al., 1992; Santolaya et al., 2013). However, a spray naturally contains 
a wide range of droplet sizes, so the smallest ones can serve as natural tracers (Breña de la Rosa et al., 1992), that is they help in distinguishing and comparing the gas and the liquid motion. Here, the turbulent kinetic energy and mean kinetic energy can serve to reveal the energetic structure of the spray (Kourmatzis et al., 2013). circumstances, so various empirical formulae were developed for different atomizer types to provide a simple methodology for estimating the spray characteristics (Lefebvre, 1989). Since droplet evaporation plays a significant role in many applications, typically, the volume-to-surface mean diameter (Sauter Mean Diameter, $S M D$ or $D_{32}$ ) is derived from measurements for spray characterization. Among those researchers, who have investigated the C-30 gas turbine atomizer, the results of Bolszo suggest that the wellknown formula of Rizk and Lefebvre for $D_{32}$ estimation (detailed in the Methods section) does not fit the atomization process well at low air-to-fuel mass flow ratio, $A L R$, values. Nakamura et al. (2008) investigated the same atomizer under a wide range of operating conditions. The comparison of their results with the predicted $D_{32}$ was not included but mentioned in their paper. A recent study on an internal mixing airblast atomizer (Chong and Hochgreb, 2015) has shown that the agreement between the measured and the predicted and the $D_{32}$ based on the formula by Rizk and Lefebvre may be reasonable. However, a significant discrepancy of the study of Chong and Hochgreb is that the calculated discharge velocity of air did not consider its further expansion downstream from the exit orifice. Nevertheless, it happens in a choked flow that discharges into the ambient. The authors assumed that the relevant velocity of atomization was limited to a 
Two basic configurations of airblast atomizer are recognized (Ashgriz, 2011): prefilming and non-prefilming ones. The prefilming design spread the liquid first into a very thin sheet or a film which is then exposed to high-velocity flowing air causing the atomization. Non-prefilming (so called plain-jet) nozzles consist of a channel with liquid, which is externally mixed with air. The prefilming nozzles produce fine spray but are difficult to manufacture, and they are less accurate over longer distances than nonprefilming nozzles. The plain-jet nozzles are used in low-to-moderate pressure environments, which is the case of this paper.

If the velocity of the atomizing air is sufficiently high, prompt atomization occurs where the droplets are generated by a rapid and violent disruption of the liquid jet (Lefebvre, 1992). In this case, the effect of liquid viscosity is negligible, and the droplet sizes are broad-ranged. The term "sufficiently high” referred to an atomizing velocity of $>20 \mathrm{~m} / \mathrm{s}$ at $A L R>0.3$ in (Lefebvre, 1992). This statement is also supported by a recent work by Chaussonnet et al. (2016). The $D_{32}$ formulae are not consistent regarding the inclusion of liquid viscosity, which is emphasized in the Global spray characterization subsection. Most of the cited and present measurement series were carried out under atmospheric conditions, but similar trends were found up to 12 bar ambient pressure by Zheng et al. (1996). They investigated airblast atomization in a real gas turbine combustion chamber at cold flow conditions. The conclusion was that the $D_{32}$ does not change significantly up to 12 bar back-pressure while the same dimensionless conditions are provided. This result allows the formulas derived for atmospheric conditions to be applied at elevated back-pressures as well. However, elevating the back-pressure alone obviously leads to a decrease in the droplet sizes (Jasuja and Lefebvre, 1994). 
The early experimental works on $D_{32}$ determination often used the diffraction technique to measure the line-of-sight integrated droplet size (Park et al., 1996; Rizk and Lefebvre, 1984), so the spatial drop size variation was not resolved. The application of phase-Doppler technique allowed the simultaneous droplet velocity measurement and added the spatial resolution into the results (Jasuja and Lefebvre, 1994; Zheng et al., 1996). The state-of-the-art phase-Doppler technique improved the detection of small particles due to the large probe aperture and the selectable spatial filters allowed to measure in dense sprays. The older PDA signal processors used the covariance analysis technique while the new generation employs the Doppler burst spectral analysis techniques based on multi-bit burst detection and multi-bit FFT signal processing. This upgrade ensures a more robust detection of all signal levels (Wigley et al., 2004). As a consequence, the state-of-the-art techniques are able to sense even two magnitudes smaller droplets than it was available few decades ago (Lefebvre, 1980). Therefore, the investigation of fine sprays became highly relevant to extend the limitations and revise of the results derived in the past.

Two sprays with identical $D_{32}$ values are not necessarily similar; their size distribution functions may differ significantly. However, this property received less scientific focus compared to the determination of $D_{32}$ (Babinsky and Sojka, 2002). The literature distinguishes the empirical method, the maximum entropy method, and the discrete probability function method for characterizing the droplet size distributions (Babinsky and Sojka, 2002). Even though the second and third mentioned methods rely on physical laws, none of them has so far been able to provide a generally acceptable prediction of the size distribution functions using only the boundary conditions of the atomization process (Liu et al., 2006; Navarro-Martinez, 2014; Tharakan et al., 2013). It is expected 
that CFD simulations of the liquid breakup will lead to a better understanding of the atomization process in the future (Tharakan et al., 2013). Therefore, the present paper aims to analyze the fit of different probability density functions, PDFs, with the experimental data over a range of atomizing pressures. According to the best knowledge of the authors, such a study is not available in the literature.

Our previous combustion studies revealed that atomization characteristics considerably affect the flame shape, pollutants, and chemiluminescence emissions (Józsa and Kun-balog, 2015; Józsa and Sztankó, 2016; Kun-Balog and Sztankó, 2015). In order to analyze both local and global spray characteristics, the plain-jet airblast atomizer was examined in cooperation with the Brno University of Technology. The work is confined to an atmospheric rig to eliminate the effect of evaporation (this will be shown later in the Methods section) and isolate the atomization process. The measurement data is available upon request.

From earlier studies, it was pointed out that spray characterization is impossible in a purely analytical way due to the involvement of several physical effects and their interaction (Lasheras et al., 1998). Hence, at first, the present paper highlights the key governing phenomena of airblast atomization through the experimental study of the droplet dynamics and the gas-liquid interactions. Secondly, the average volume-tosurface droplet size is calculated in order to review the widely applied empirical formulae in the literature for $D_{32}$ estimation by airblast atomization. Thirdly, three different droplet size distribution functions are analyzed and compared at various atomizing pressures.

\section{Methods}



including both empirical and physically valid ones. However, all of them contain at least one constant which is to be determined based on the experimental results. Secondly, three droplet size distribution functions are detailed, these are fitted to the measured data. This is followed by the introduction of stability criteria for droplets based on the shear and the turbulent Weber number. Finally, the evaporation of droplets, which might influence the analysis of the measured data, is discussed.

\section{Záložka není definována.)}

$$
D_{32}=d(1+1 / A L R)\left(A \cdot W e_{A}^{-0.5}+B \cdot O h_{L}\right),
$$

(1Chyba! 
where, $A$ and $B$ are empirical constants. The exponents in Eq. (1) were modified in order to follow the measured trends more accurately by (Rizk and Lefebvre, 1984):

$D_{32}=d\left[C \cdot W e_{A}^{-0.4}(1+1 / A L R)^{0.4}+E \cdot O h_{L}(1+1 / A L R)\right],(2$ Chyba! Záložka není definována.)

where $C=0.48$ and $E=0.15$ are widely used constants in the literature of atomization. Originally, Eq. (2) was derived by atomizing kerosene, gas oil, and blend oils in the range of $u=10-120 \mathrm{~m} / \mathrm{s}, D_{32}=15-110 \mu \mathrm{m}, A L R=2-8$, atomizing gauge pressure, $p_{g}=0.01-$ 0.077 bar. The measurement technique used was light-scattering interferometry. A more recent formula for $D_{32}$ estimation for airblast atomization by a high-speed gas stream was published by Varga et al. (2003):

\section{není definována.)}

$$
D_{32}=\frac{0.68 F^{0.5}\left(\rho_{L} v_{A}\right)^{0.25} \sigma^{0.5}}{\rho_{A}^{0.75}\left[u_{A}\left(1+\sqrt{\rho_{A} / \rho_{L}}\right)-u_{L}\right] u_{A}^{0.25}},(3 \text { Chyba! Záložka }
$$

where $F$ is a constant and $v$ is the kinematic viscosity. Note that the dimension of $F$ is square root meter by dimension analysis. The velocity regime examined was $u=30-165$ $\mathrm{m} / \mathrm{s}$. They estimated that $F=0.055 \mathrm{~m}^{0.5}$. Comparing Eqs. (2) and (3), shows that the most significant difference is that (3) contains the viscosity of the atomizing air instead of that of the liquid phase, and the liquid jet diameter is absent. The exponent of the surface tension is 0.5, similar to that of Eq. (1) through the Weber number. The following formula was derived by Lefebvre (1992) for prompt atomization. However, it has not been validated by any researcher since then. 


$$
D_{32}=\frac{3}{2 / d+G \rho_{L} u_{A}^{2} /[4 \sigma(1+1 / A L R)]},
$$

168 where $G$ is the modified efficiency of the atomizer. Interestingly, only several papers 169 discuss airblast atomization under supersonic conditions, see, e.g., (Chong and Hochgreb, 2015; Kihm and Chigier, 1991; Park et al., 1996; Tsai and Viers, 1990). The required gauge pressure to achieve a supersonic atomizing jet is 0.89 bar, assuming the adiabatic expansion of air at ambient conditions, calculated by Eq. (5):

$$
p_{g, c r}=p_{0}\left[\left(\frac{2}{\gamma+1}\right)^{\frac{\gamma}{\gamma-1}}+1\right]
$$

where $p_{0}$ is the ambient pressure, $\gamma$ is the adiabatic exponent, and subscript $c r$ denotes the critical value. It was shown previously that the expansion through the nozzle of the present burner can be considered as adiabatic (Józsa and Csemány, 2016). As for such operation, Park et al. suggested the formula for $D_{32}$ estimation as follows:

$$
D_{32}=\frac{12 d}{8+W e_{L} /[(1+1 / \eta \cdot A L R)]}
$$

where $\eta$ is the energy transfer efficiency which is now a variable unlike in the case of investigated:

$$
\eta=H \dot{m}_{L}^{0.773}\left[\left(p_{t} / p_{0}\right)^{3}-15.1\left(p_{t} / p_{0}\right)^{2}+65\left(p_{t} / p_{0}\right)\right],
$$


where $p_{t}$ is the total pressure and $H$ is a constant. Although there were several other

formulae developed before the 1980s, the available measurement techniques considerably

limited the detection of the smallest droplets. Hence, the present paper is confined to the

validation of results based on laser measurement techniques. The five different equations

for $D_{32}$ estimations will be validated and analyzed in the Global spray characterization subsection of Results and Discussion section.

Droplet size distribution functions

Typically, airblast atomization is characterized by the gamma archetype

distribution functions (Villermaux, 2004). Equations (8)-(10) present the three PDFs that are fitted to the current measurement data. These are the gamma $(\Gamma)$, the Rosin-Rammler (RR, also known as Weibull), and the Nukiyama-Tanasawa (NT) PDFs, respectively.

201

202

203

204

205

206

207

208

209

210

$$
f(D)_{\Gamma}=D^{a-1} /\left[b^{a} \Gamma(a)\right] \cdot \exp (-D / b)(8 \text { Chyba! Záložka }
$$

není definována.)$$
f(D)_{R R}=b / a \cdot(D / a)^{b-1} \cdot \exp \left[-(D / a)^{b}\right]
$$$$
f(D)_{N T}=a D^{g} \cdot \exp \left(-b D^{q}\right)(10 \text { Chyba! Záložka není }
$$

\section{definována.)}

Equations (7) and (8) are two-parameter PDFs while the Nukiyama-Tanasawa is a fourparameter one. However, $g=2$ was assumed in Eq. (10) according to the literature data (Lefebvre, 1989; Xiangui and Tankin, 1987), resulting in a three-parameter PDF. 
218

219

220

221

222

223

224

225

226

227

228

229

230

231

232

233

234

\section{Droplet stability criteria}

The initial disintegration of the liquid jet, called a primary atomization, results in liquid fractions that may undergo a secondary atomization if the critical Weber number is exceeded. Lasheras et al. (1998) suggested considering both the effect of shear and turbulence, noted by $s$ and $t$ subscripts respectively. The corresponding Weber numbers are (Galinat et al., 2005; Lasheras et al., 1998):

where $\varepsilon$ is the turbulent dissipation rate. It is calculated as follows:

$$
\begin{gathered}
W e_{s}=\rho_{L}\left(u_{A}-u_{L}\right)^{2} D / \sigma \\
W e_{t}=2 \rho_{A} \varepsilon^{2 / 3} D^{5 / 3} / \sigma
\end{gathered}
$$

$$
\varepsilon=T K E^{3 / 2} / l
$$

where TKE is the turbulent kinetic energy and $l$ is the turbulent length scale which is calculated as $3.8 \%$ of the hydraulic diameter of the nozzle in the case of annular flows (Sciences et al., 2011). The determination of the turbulent kinetic energy, TKE, is detailed in Eq. (14) while Eq. (15) shows the calculation method of the previously mentioned mean kinetic energy, $M K E$.

$$
\begin{aligned}
& T K E=0.5\left[\overline{\left(u_{z}^{\prime}\right)^{2}}+\overline{\left(u_{r}^{\prime}\right)^{2}}+\overline{\left(u_{t}^{\prime}\right)^{2}}\right], \\
& M K E=0.5\left[\left(\overline{u_{z}}\right)^{2}+\left(\overline{u_{r}}\right)^{2}+\left(\overline{u_{t}}\right)^{2}\right],
\end{aligned}
$$


where $u$ is the absolute velocity, $z, r$, and $t$ subscripts represent the axial, radial, and tangential coordinates, respectively. The primes serve for the fluctuations around the temporal average while the overbars indicate the ensemble averages. The maximum stable droplet size can be estimated by Eqs. (11) and (12):

$$
D_{\text {max }}=\min \left\{\frac{\sigma W e_{s, c r}}{\left[\rho_{L}\left(u_{A}-u_{L}\right)^{2}\right]},\left[\frac{\sigma W e_{t, c r}}{\rho_{A}}\right]^{3 / 5} \varepsilon^{-2 / 5}\right\}
$$

Here, the subscript $c r$ denotes the critical values. $W e_{s, c r}=12$ and $W e_{t, c r}=0.59$ were used in the present paper based on a previous investigation of diesel oil droplet exposed in a high-velocity air stream (Hinze, 1955; Lefebvre, 1989).

\section{Effect of evaporation}

The evaporation of the spray was calculated based on the $D^{2}$-law, detailed by Lefebvre (1989). This method was chosen due to its simplicity, the investigated conditions, and considering the measured quantities. Firstly, the residence time of a single droplet was calculated based on the measured velocities at various axial distances. Secondly, its initial diameter was determined, assuming that the droplet is formed at the discharge position, it avoids the secondary breakup, and the droplet fully evaporates in the measured region. Based on the calculation, droplets with $D<0.161 \mu \mathrm{m}$ may evaporate completely. It is advisable to use the droplet size that requires ten times larger residence than it is present for droplets bursting through the investigated regime of the spray (Aliabadi et al., 2011). In this case, the minimum droplet size to consider becomes $D=0.51 \mu \mathrm{m}$ which refers to $>99.8 \%$ of the measured droplets by number fraction. The diameter decrease of $D=0.51,1$, and $2 \mu$ m droplets were $<5 \%$, $<1.3 \%$, and $<0.3 \%$, 
respectively. In order to consider the convective effects, also documented by Lefebvre (1989), the Reynolds number of the droplets was determined first which never exceeded 1000. The small droplets have low inertia, therefore, they rapidly reach the velocity of the surrounding gas and enter the Stokes flow regime. This results in a $<1 \%$ increase in the evaporation properties and could be neglected here. Consequently, the authors assume that the spray evaporation does not affect the evaluation of the measurement data. The analysis of droplet evaporation in a hot gas flow using the same burner was published elsewhere (Józsa and Csemány, 2016).

\section{Experimental setup}

The experimental atmospheric test rig is shown in Fig. 1. The liquid was standard diesel fuel $\left(v=3.5 \mathrm{~mm}^{2} / \mathrm{s}, \rho=825 \mathrm{~kg} / \mathrm{m}^{3}, \sigma=0.025 \mathrm{~N} / \mathrm{m}\right.$ at $\left.20^{\circ} \mathrm{C}\right)$. The atomizing air passed from the central compressed air system through a pressure regulator followed by two mass flow meters towards the atomizer. The following atomizing gauge pressures, $p_{g}$, were investigated: $0.3,0.5,0.7,0.9,1.1,1.6,2.1,2.6$, and 3.1 bar. The lowest value was selected based on the criteria of stable combustion in the hot test cases (Józsa and Kun-balog, 2015; Józsa and Kun-Balog, 2017; Kun-Balog and Sztankó, 2015). To feed the fuel into the atomizer, a pressurized fuel tank was used. A control valve and a Coriolis mass flow meter were applied in order to set a constant $0.35 \mathrm{~g} / \mathrm{s}$ fuel mass flow rate. Both fluid lines were equipped with pressure transducers and thermocouples. The investigated $A L R$ regime was $0.78-2.3$.

The cross section of the currently investigated plain-jet airblast atomizer is shown in Fig. 2. It contains a $0.4 \mathrm{~mm}$ diameter fuel pipe and a concentric annular nozzle (with $0.8 \mathrm{~mm}$ inner and $1.6 \mathrm{~mm}$ outer diameter). The fuel was discharged from the central 
channel while the air flow surrounded the liquid core and accelerated the fuel stream. Thus, the fuel jet is shattered into smaller fractions due to the liquid-air interactions.

A 2D Fiber based Phase-Doppler Anemometer (PDA) made by Dantec Dynamics was used for measuring the droplet size and axial and radial velocity components, shown in Fig. 3. This also indicates a series of measuring points through the spray made by moving the atomizer radially using a computer controlled traverse. Spectra Physics Stabilite 2017 Argon laser produced a laser beam which was split by 60X41 Transmitter into its individual color components $(488.0 \mathrm{~nm}, 514.5 \mathrm{~nm})$ and each color divided into two beams. A Brag cell was implemented in the transmitter to provide a frequency shift of $40 \mathrm{MHz}$ to one beam from each pair. Transmitting optics 60X81 2D 85 mm with 50X82 beam translator and fiber PDA receiver optics 57X50 112 mm diameter with spatial filter were used. Focal lengths were $500 \mathrm{~mm}$ for both the transmitting and the receiving optics, and the scattering angle was $70^{\circ}$, which is Brewster's angle, such that the refracted light is the dominant light scattering mode. The signals were processed by the BSA P80 flow and particle processor. The modular instrument was configured for the measurement in the dense spray containing small droplets. The droplet velocities varied significantly with the inlet conditions, so the system parameters were set individually for different axial distances from the atomizer exit orifice and the inlet pressure. The maximum measured droplet sizes was set to $64.1 \mu \mathrm{m}$ with size resolution of $\pm 0.05 \mu \mathrm{m}$, and the uncertainty of individual droplet size measurement was $\pm 0.5 \mu \mathrm{m}$. The axial and radial velocity range was set from $0-64 \mathrm{~m} / \mathrm{s}$ to $0-309 \mathrm{~m} / \mathrm{s}$ and from $0-46 \mathrm{~m} / \mathrm{s}$ to $0-98 \mathrm{~m} / \mathrm{s}$ respectively, considering the effect of the axial distance from the atomizer and the inlet pressure on the maximum droplet velocity. The velocity resolution was $0.002 \%$, and the uncertainty was less than $1 \%$ of the selected range. The PDA system was set to acquire 20,000 particles 
or measure for at least 15 seconds in low-density regions. According to the preliminary results (not shown here), the spray was found to be symmetrical.

The PDA measurements were carried out at four axial distances below the nozzle, $z=10,15,26.7$, and $50 \mathrm{~mm}$, with thirteen radial points, $r$, at $z=10-26.7 \mathrm{~mm}$ and fifteen at $z=50 \mathrm{~mm}$. For 10 and $15 \mathrm{~mm}$ downstream distances, the step was $1 \mathrm{~mm}$ between the measured points and $2 \mathrm{~mm}$ at $\mathrm{z}=26.7$ and $50 \mathrm{~mm}$. Considering the highest atomization pressure, the droplet velocities at $z=10 \mathrm{~mm}$ were close to the limitations of the PDA ( $\sim 300 \mathrm{~m} / \mathrm{s}$ ) imposed by the optical geometry and the processor. Hence, it was not possible to measure closer than $10 \mathrm{~mm}$ to the nozzle. The $\mathrm{z}=26.7 \mathrm{~mm}$ position was chosen as a typical distance since it is the inner diameter of mixing tube which was removed previously, similar to the experiments of Nakamura et al. (2008). $z=50 \mathrm{~mm}$ was a sufficient axial distance to ensure a fully developed spray.

\section{Results and discussion}

Firstly, this chapter focuses on the characterization of the droplet dynamics at various atomizing pressures. Secondly, the interactions between the gas and the liquid phase are discussed. Thirdly, the $D_{32}$ values are calculated at each measurement point as a function of atomizing pressure, to reveal the averaged evolution of the spray. This is followed by the stability analysis, based on the Weber number criteria, detailed in the Methods chapter. Then the integral $D_{32}$ values are determined. Formulae mentioned above for estimating $D_{32}$ (Eqs. (1)-(4) and (6)) were fitted to the fully developed spray data at $z=50 \mathrm{~mm}$. Finally, the three commonly used PDFs in the atomization literature were also evaluated at $z=50 \mathrm{~mm}$. 


\section{Droplet dynamics}

According to the literature, the liquid is disrupted by the shear action of the flowing gas and the newly created liquid fractions are further accelerated which leads to the formation of ligaments; these then break up into smaller droplets (Lasheras et al., 1998).

Figure 4 shows typical radial-axial velocity scatter plots at $p_{g}=0.9$ bar for all four axial distances, indicating the spray development. The near-nozzle region $(z=10 \mathrm{~mm})$ is characterized by a broad spectrum of the radial droplet velocity. $D<20 \mu \mathrm{m}$ particles reach higher radial velocities than the larger ones, due to the highly turbulent atomizing jet (Lasheras et al., 1998), shown in Fig. 4a. It is supported by the fact that the majority of $D<10 \mu \mathrm{m}$ droplets have equal or higher axial velocities than that of $D>20 \mu \mathrm{m}$ particles in the vicinity of the nozzle. The velocity of small particles significantly reduces as the spray evolves. Interestingly, Fig. $4 \mathrm{~d}(\mathrm{z}=50 \mathrm{~mm})$ shows that the large droplets keep their momentum which is in good agreement with the literature (Aliabadi et al., 2011). When comparing Figs. 4a-d, the transition of droplet velocity distribution is revealed. In the near-nozzle region, high-velocity droplets are generally smaller than $15 \mu \mathrm{m}$. However, as the spray develops, the small droplets lose their momentum due to their interaction with the ambient air. Note that the Phase-Doppler technique is only able to precisely size spherical particles, so the PDA results on particle size in the atomizing spray (at some cases of the short distances from the exit orifice, $z=10$ and $15 \mathrm{~mm}$ ) give only a rough estimate of the droplet size.

Figure 5 shows scatter plots at $p_{g}=0.3,0.9,2.1$, and 3.1 bar at $z=50 \mathrm{~mm}$. The low-pressure regimes are characterized by a strong axial flow while the radial component 
remains relatively weak. With an increase of the atomization pressure, the velocity grows in both axial and radial direction together with the turbulence, as discussed below.

\section{Mean and turbulent kinetic energies}

In order to distinguish between the liquid and the gas phase, droplets with $D \leq 5 \mu \mathrm{m}$ have been filtered to represent the motion of the latter phase (Breña de la Rosa et al., 1992). Sanchez et al. (2000) used spray droplets with sizes under $5 \mu \mathrm{m}$ as tracers of the gas velocity field as well. In the present case, droplets of $D \leq 3 \mu \mathrm{m}$ were selected from the measured PDA records and their velocities were averaged. These small droplets are characterized by the Stokes numbers typically $S t k \ll 1$, so that they smoothly follow the streamlines due to their low inertia. Figure 6 shows the TKE, $M K E$, axial, and radial velocity profiles at various axial distances at $p_{g}=0.9$ bar, (Figure $6, \mathrm{a}-\mathrm{d}$ ), and at different atomizing pressures at $z=50 \mathrm{~mm}$, (Figure 6, e-h). There is a clear trend of the axial and radial velocities decaying for both the liquid and the gas phase with growing axial distances. The overshooting phenomenon occurs in twin-fluid atomization when the droplets lose their momentum slower than the atomizing medium and in later regions the droplet velocity might exceed the gas phase velocity (Lasheras et al., 1998). Here, by separating the motion of the two phases, the overshooting phenomenon is clearly observable in both the velocity and the MKE trends.

When examining the TKE and the MKE profiles as a function of the operating pressure, it can be seen that their values are directly proportional to the atomizing pressure, especially on the centerline of the spray. The TKE profiles are very similar in both the liquid and gas phases. For an atomizing pressure of 0.3 bar, the maximum value of TKE is concentrated in the center of the spray. When the pressure increases, the 
maximum value moves radially from the center to $r=2 \mathrm{~mm}$. The $M K E$ profiles show that the mean energy is concentrated mainly in the liquid phase and in the vicinity of the axis. The difference between $M K E$ of liquid and gas phase decreases with the growth of the atomizing pressure. It points to the fact that the kinetic energy is transferred from the gas phase to the liquid more intensively under the high-pressure operating regimes which are characterized by higher TKEs and smaller droplets.

\section{Droplet size-velocity correlations}

Figure 7 shows the influence of the atomizing pressure on the relation between the droplet size and the axial velocity which is the dominant velocity component in the investigated case. These results were obtained at $z=50 \mathrm{~mm}$ and radial distance, $r=0$ $\mathrm{mm}$. The overshooting phenomenon is also confirmed by Fig. 7 while the average velocity of the droplets increases with their size. Moreover, the slope of the profiles increases with the atomizing pressure. It can be explained by the fact that the discharge velocity increases with the atomizing pressure. The droplet size is negatively correlated with the operating pressure. With the growth of the atomizing pressure, the droplets are smaller, and the velocity fluctuations increase in parallel with the TKE.

\section{Global spray characterization}

Figure 8 shows the evolution of the spray at four atomizing pressures and four axial distances. At $z=10$ and $15 \mathrm{~mm}$ and $p_{g}=2.1$ and 3.1 bar, the large droplet sizes at the center clearly show the ongoing secondary atomization process. However, at $p_{g}=0.3$ and 0.9 bar, such a peak is absent, probably due to the lower discharge velocities that result in longer residence times at these axial distances, allowing more time for 
atomization. Hence, a nearly complete state of the spray was measured at $p_{g}=0.3$ and 0.9 bar at $\mathrm{z}=10$ and $15 \mathrm{~mm}$ axial distances and atomizing pressures. The evolution of the spray at $p_{g}=0.3$ bar shows only a slight decrease in $D_{32}$ at the center. Otherwise, it can be considered as fully developed, based on the nearly constant values of $D_{32}$ in the downstream regions. The spray needs a more axial distance to develop fully at high atomizing pressures, indicated by the data of $p_{g}=2.1$ and 3.1 bar. Typically, the larger droplets that move to the periphery do not undergo a secondary breakup; however, they represent only a small fraction of droplets. Nevertheless, these droplets may considerably influence the combustion efficiency and pollutant emission of a burner. It occurs when unevaporated droplets or a highly heterogeneous fuel-air mixture is present at the flame front. High atomizing pressure ensures not only smaller droplets but also a more even spray. It should be kept in mind, that the higher the inlet pressure, the higher the enthalpy available for the atomization process. So, while the droplet sizes would reduce with the confirms that a larger droplet at the periphery may remain stable since the maximum stable droplet size, $D_{\max }$, increases with the radial distance. At $p_{g}=2.1$ and 3.1 bar, the stable droplet sizes at $r=0$ and $2 \mathrm{~mm}$ close to the $D_{32}$ values determined from the measurements. Note that the shear Weber number, defined by Eq. (11), was the dominant limiting factor, assuming a constant surface tension. However, the temperature of the atomizing medium, considering an adiabatic expansion, may drop to $200 \mathrm{~K}$ at $p_{g}=3.1$ bar, resulting in a notable drop in the droplet temperature. Consequently, the increasing 
surface tension due to low temperature might stabilize the central droplets. In order to check this hypothesis, further analyses should be carried out.

Validation of $D_{32}$ estimating formulae

To characterize a spray with a single typical diameter, the integral $D_{32}\left(I D_{32}\right)$ is determined, detailed in ref. (Jedelsky and Jicha, 2014). Figure 10a shows the $I D_{32}$ for all operating regimes and all measured axial distances. At $z=10 \mathrm{~mm}$, the $I D_{32}$ decreases with pressure first, until reaching a minimum at $p_{g}=1.6$ bar and the tendency turns, showing an increase with the atomizing pressure. The same behavior was observed at $z=15 \mathrm{~mm}$. At $z=10,15$, and $26.7 \mathrm{~mm}$, there is an apparent break in the $I D_{32}$ trends at $p_{g}=0.9$ bar.

This is the first atomization pressure where the critical pressure ratio, defined by Eq. (5), was exceeded. It suggests that there is only a slight interaction between the spray and the emerging shock waves, which is in agreement with the literature (Kihm and Chigier, 1991). (4) and (6) and the measurement data at $z=50 \mathrm{~mm}$. Among them, Eq. (1) resulted in the best fit at $A=0.61$ and $B=0.041$ with a coefficient of determination, $R^{2}=0.997$. The small value of the coefficient of $O h$ number suggests that the ongoing atomization is prompt-type, proposed by Lefebvre (1992), Varga et al. (2003), and Chaussonnet et el. (2016). Therefore, the fit was repeated at $B=0$, resulting in $A=0.66$ and a negligible decrease in $R^{2}$. This variation of Eq. (1) is the simplest possible formula for $D_{32}$ estimation among all the investigated equations.

Equation (2) with the original constants $(C=0.48$ and $E=0.15$ (Rizk and 449 Lefebvre, 1984), denoted as Eq. (2) orig. in Fig. 10b) resulted in $R^{2}=0.0929$. It shows 
that the direct application of this widely recognized formula at elevated atomization pressures significantly overestimates $D_{32}$. By modifying the constants, the best fit ( $\left.R^{2}=0.926\right)$ was achieved at $C=0.47$ and $E=0$. It also supports the fact that the effect of the liquid viscosity, included in the $O h$ number, is not significant here. The superiority of Eq. (2) is indicated by the negligible change of $C$ compared to its original value, regardless that the formula was tested at a significantly higher atomizing pressures than it was originally performed by Rizk and Lefebvre (1984).

Considering that they suggested $F=0.055 \mathrm{~m}^{0.5}$, a significant variation can be most probably addressed to the different nozzle geometry or to a higher discharge velocities in the present case $\left(u_{A}=208-445 \mathrm{~m} / \mathrm{s}\right.$ considering adiabatic expansion at $p_{g}=0.3-3.1$ bar in contrast with $u_{A}=30-165 \mathrm{~m} / \mathrm{s}$ in the experiments of Varga et al. (2003)). Due to the more than five factor difference in the value of $F$, it is safer to use of either Eq. (1) or (2) in practice.

Equation (4) by Lefebvre (1992) resulted in $R^{2}=0.702$ at $G=0.00082$, showing a less accurate fit, probably due to the fact the value of $G$ should not be constant while it is the modified atomization efficiency which alters with $p_{g}$, shown by (Jedelsky and Jicha, 2014, 2013). This equation was significantly outperformed by Eqs. (1)-(3). $R^{2}=0.0418$ and $H=2.04$ - even though it considers the atomization efficiency in the 470 function of $p_{g}$. This result is a surprise while Eqs. (6) and (7) were derived under very similar atomizing conditions $\left(p_{g}=1-4 \mathrm{bar}\right)$. 
$474 A L R=0.78-2.3$ and Mach number, $M a=u_{A} / c=0.6-1.6$. Here, $c$ is the speed of sound, 475 and the calculated values are based on the measurement conditions, considering an adiabatic expansion of the atomizing jet.

Droplet size distribution

Figures 11a and $\mathrm{b}$ show the average parameters of the three PDFs (Eqs. (8)-(10))

by a curve fitting method. Measurement points with insufficient data (i.e. less than 20,000 peripheral regions showed varying and irregular droplet distributions. Practically, it means that $-10 \mathrm{~mm} \leq r \leq 10 \mathrm{~mm}$ regime was taken into account at all atomizing pressures and $z=50 \mathrm{~mm}$. All the parameters were weighted by the data rate, hence, the error bars indicate the mean square weighted deviations. By substituting the trends into Eqs. (8)(10), it is clear that the values of all exponents increase, showing that the spray is less even at elevated atomizing pressure, in agreement with the literature (Babinsky and Sojka, 2002). This behavior was qualitatively supported also by Fig. 8. It should be noted that the four-parameter NT distribution function was also analyzed, but the excessive change of the parameters (i.e., few magnitudes in a single $p_{g}$ at $z=50 \mathrm{~mm}$ ) lead to the exclusion of that function. Interestingly, the best fit was achieved by the $\Gamma$ function with $R^{2}=0.983$ on average, outperforming both RR $\left(R^{2}=0.962\right)$ and NT $\left(R^{2}=0.982\right)$ PDFs, shown in Fig. 11c. The value of $R^{2}$ increases with the atomizing pressure as the spray becomes less averaged parameters is that the integral of these PDFs was not equal to unity. At $p_{g}=2.1$ bar, this value decreased to 0.65 . However, both $\Gamma$ and RR PDFs exactly fulfill this condition over the whole range. Nevertheless, at 0.3 and 0.5 bar atomizing pressure, the 
integral of the NT PDF was above 0.9, making it an optional choice for this region. Furthermore, in this region, NT shows a better fit to the droplet distributions while it is able to incorporate a wider range of droplet sizes, which is the situation at low atomizing pressures.

502

503

\section{Conclusions}

504

A plain-jet airblast atomizer was investigated on an atmospheric test rig using the PhaseDoppler technique. Measurements of droplet size and axial and radial velocity components were made on various atomizing pressures and axial distances from the nozzle. Spray evolution, droplet dynamics, and turbulent properties of the gas and the liquid were analyzed. Five empirical and semi-empirical formulae for the calculation of the volume-to-surface diameter, $D_{32}$, were investigated to examine how they describe the physics of atomization and for their range of validity. This analysis was followed by the evaluation of size distributions in the spray. Therefore, by fine-tuning these leads to a better understanding of droplet formation and helps in developing better models and conclusions were derived:

1. The variation of droplet radial velocities increases significantly with the atomizing pressure. This is also indicated by the turbulent and mean kinetic energy trends which were found to be proportional to the atomizing pressure.

2. The spray clearly shows the phenomenon of overshooting, i.e., when droplets lose their kinetic energy slower than the gas phase. This is already described by, e.g. (Lasheras et al., 1998). Hence, downstream from the nozzle, certain droplets might have a higher velocity than the gas. 
3. The most intense atomization is located in the central region, while droplets at the periphery are highly stable. Therefore, high atomizing pressures ensure a less even spray while already small droplets move to the outer regions in the vicinity of the nozzle. The stability analysis, based on the turbulent and shear Weber number calculations, similarly shows that the peripheral droplets are highly stable while the intense secondary atomization is confined to the spray centerline.

4. At $z=50 \mathrm{~mm}$ axial distance, the spray is considered to be fully developed. The $D_{32}$ estimations showed that Eqs. (1)-(3) can be reasonably fitted to the measurement data. However, Eq. (1) is recommended for practical use by neglecting the viscosity term due to its simplicity and excellent fit. The validity of this formula for an exit Mach number is $M a=0.6-1.6$ and air-to-fuel mass flow ratio, $A L R=0.78-2.3$, assuming that the ambient pressure does not affect the $D_{32}$ significantly.

5. Among the Nukiyama-Tanasawa, NT, Rosin-Rammler, RR, and gamma, $\Gamma$, probability distribution functions the latter describes most closely the averaged droplet size distribution of the spray at $z=50 \mathrm{~mm}$. However, the NT PDF performed slightly better at $p_{g}=0.3$ and 0.5 bar. The most significant discrepancy of this PDF was the inability to give unity for the integral of the function, especially at higher atomizing pressure values. This condition was exactly fulfilled by both the RR and the $\Gamma$ PDF at all setups.

At this moment, the authors of this paper ask the fellow researchers in the field of atomization to test the validity of our suggestions for $D_{32}$ estimation in other airblast atomizer configurations (including prefilming ones besides plain-jet). The goal is to 
provide an appropriate equation for practical users in the high-velocity atomization regime.

The currently investigated atomizer was used for crude rapeseed oil combustion previously (Józsa and Kun-balog, 2015; Józsa and Kun-Balog, 2017). Therefore, the investigation of the atomization properties of crude vegetable oils and other highviscosity renewable fuels are recommended since their atomization properties might differ from those of the conventional liquid fuels. Such experiments may help to understand the spray formation in greater detail. As the present research is not confidential, the measurement data is available upon request.

Acknowledgements

This work has been supported by the project №. GA15-09040S funded by the

Czech Science Foundation and the project LO1202 NETME CENTRE PLUS with the

financial support from the Ministry of Education, Youth and Sports of the Czech Republic under the "National Sustainability Program I" and the Visegrád 3-111-0027 Strategic grant, V4 Green Energy Platform. The authors are thankful for the valuable insights of Dr. Graham Wigley.

\section{References}

Aliabadi, A.A., Lim, K.W.J., Rogak, S.N., Green, S.I., 2011. Steady and Transient Droplet Dispersion in an Air-Assist Internally Mixing Cone Atomizer. At. Sprays 21, 1009-1031. doi:10.1615/AtomizSpr.2012004415

Ashgriz, N., 2011. Hand book of atomization and sprays, Springer. Springer Science \& Business Media, LLC. doi:10.1007/978-1-4419-7264-4

Babinsky, E., Sojka, P.E., 2002. Modeling drop size distributions. Prog. Energy Combust. Sci. 28, 303-329. doi:10.1016/S0360-1285(02)00004-7

Bolszo, C.D., 2005. Investigation of Atomization, Mixing and Pollutant Emissions for a Microturbine Engine. UCI Undergrad. Res. J. VIII, 13-22.

Breña de la Rosa, A., Wang, G., Bachalo, W.D., 1992. The Effect of Swirl on the 
Velocity and Turbulence Fields of a Liquid Spray. J. Eng. Gas Turbines Power $114,72-81$.

Chaussonnet, G., Vermorel, O., Riber, E., Cuenot, B., 2016. A new phenomenological model to predict drop size distribution in Large-Eddy Simulations of airblast atomizers. Int. J. Multiph. Flow 80, 29-42. doi:10.1016/j.ijmultiphaseflow.2015.10.014

Chong, C.T., Hochgreb, S., 2015. Effect of Atomizing Air Flow on Spray Atomization of an Internal-Mix Twin-Fluid Atomizer. At. Sprays 25, 657-673. doi:10.1615/AtomizSpr.2015011361

Correa, S.M., 1993. A Review of NOx Formation Under Gas-Turbine Combustion Conditions. Combust. Sci. Technol. 87, 329-362. doi:10.1080/00102209208947221

Galinat, S., Masbernat, O., Guiraud, P., Dalmazzone, C., Noïk, C., 2005. Drop break-up in turbulent pipe flow downstream of a restriction. Chem. Eng. Sci. 60, 65116528. doi:10.1016/j.ces.2005.05.012

Gupta, K.K., Rehman, a., Sarviya, R.M., 2010. Bio-fuels for the gas turbine: A review. Renew. Sustain. Energy Rev. 14, 2946-2955. doi:10.1016/j.rser.2010.07.025

Hinze, J.O., 1955. Fundamentals of the hydrodynamic mechanism of splitting in dispersion processes. AIChE J. 1, 289-295. doi:10.1002/aic.690010303

Ikeda, Y., Tsuchimoto, N., Kawahara, N., Nakajima, T., 1997. Fuel Droplet Dynamics and Dispersion of Practical Twin-Fluid Atomizer for Oil Furnace. Int. J. Fluid Mech. Res. 24, 138-148. doi:10.1615/InterJFluidMechRes.v24.i1-3.140

Jasuja, A.K., Lefebvre, A.H., 1994. Influence of ambient pressure on drop-size and velocity distributions in dense sprays. Symp. Combust. 25, 345-352. doi:10.1016/S0082-0784(06)80661-2

Jedelsky, J., Jicha, M., 2014. Energy considerations in spraying process of a spill-return pressure-swirl atomizer. Appl. Energy 132, 485-495. doi:10.1016/j.apenergy.2014.07.042

Jedelsky, J., Jicha, M., 2013. Energy conversion during effervescent atomization. Fuel 111, 836-844. doi:10.1016/j.fuel.2013.03.053

Józsa, V., Csemány, D., 2016. Evaporation of renewable fuels in a lean premixed prevaporized burner. Period. Polytech. Mech. Eng. 60, 82-88. doi:10.3311/PPme.8564

Józsa, V., Kun-balog, A., 2015. Spectroscopic analysis of crude rapeseed oil flame. Fuel Process. Technol. 139, 6-11. doi:10.1016/j.fuproc.2015.08.011

Józsa, V., Kun-Balog, A., 2017. Stability and emission analysis of crude rapeseed oil combustion (submitted manuscript). Fuel Process. Technol. 156, 204-210. doi:10.1016/j.fuproc.2016.11.004

Józsa, V., Sztankó, K., 2016. Flame emision spectroscopy measurement of a steam blast and air blast burner. Therm. Sci. 1-11.

Kihm, K.D., Chigier, N., 1991. Effect of Shock Waves on Liquid Atomization of a Two-Dimensional Airblast Atomizer. At. Sprays 1, 113-136.

Kourmatzis, A., Masri, A.R., 2014. The influence of gas phase velocity fluctuations on primary atomization and droplet deformation. Exp. Fluids 55. doi:10.1007/s00348013-1659-3

Kourmatzis, A., Pham, P.X., Masri, A.R., 2013. Air assisted atomization and spray density characterization of ethanol and a range of biodiesels. Fuel 108, 758-770. doi:10.1016/j.fuel.2013.01.069 
Kun-Balog, A., Sztankó, K., 2015. Reduction of pollutant emissions from a rapeseed oil fired micro gas turbine burner. Fuel Process. Technol. 134, 352-359. doi:10.1016/j.fuproc.2015.02.017

Lasheras, J.C., Villermaux, E., Hopfinger, E.J., 1998. Break-up and atomization of a round water jet by a high-speed annular air jet. J. Fluid Mech. 357, 351-379. doi:10.1017/S0022112097008070

Lefebvre, A.H., 1992. Energy Considerations in Twin-Fluid Atomization. J. Eng. Gas Turbines Power 114, 89-96.

Lefebvre, A.H., 1989. Atomization and Sprays. Hemisphere Publishing Corporation.

Lefebvre, A.H., 1980. Airblast atomization. Prog. Energy Combust. Sci. 6, 233-261. doi:10.1016/0360-1285(80)90017-9

Lefebvre, A.H., Ballal, D.R., 2010. Gas turbine combustion, third. ed. CRC Press, Boca Raton.

Liu, H.-F., Gong, X., Li, W.-F., Wang, F.-C., Yu, Z.-H., 2006. Prediction of droplet size distribution in sprays of prefilming air-blast atomizers. Chem. Eng. Sci. 61, 17411747. doi:10.1016/j.ces.2005.10.012

Navarro-Martinez, S., 2014. Large eddy simulation of spray atomization with a probability density function method. Int. J. Multiph. Flow 63, 11-22. doi:10.1016/j.ijmultiphaseflow.2014.02.013

Park, B.K., Lee, J.S., Kihm, K.D., 1996. Comparative study of twin-fluid atomization using sonic or supersonic gas jets. At. Sprays.

Prussi, M., Chiaramonti, D., Riccio, G., Martelli, F., Pari, L., 2012. Straight vegetable oil use in Micro-Gas Turbines: System adaptation and testing. Appl. Energy 89, 287-295. doi:10.1016/j.apenergy.2011.07.031

Rizk, N.K., Lefebvre, A.H., 1984. Spray Characteristics of Plain-Jet Airblast Atomizers. J. Eng. Gas Turbines Power 106, 634-638.

Sanchez, M.L., Castro, F., Tinaut, F. V., Melgar, A., 2000. Considerations on the gasphase velocity field in a nonevaporating diesel spray. At. sprays 10, 529-543. doi:10.1615/AtomizSpr.v10.i6.10

Santolaya, J.L., Aísa, L.A., Calvo, E., García, I., García, J.A., 2010. Analysis by droplet size classes of the liquid flow structure in a pressure swirl hollow cone spray. Chem. Eng. Process. Process Intensif. 49, 125-131. doi:10.1016/j.cep.2009.12.003

Santolaya, J.L., García, J.A., Calvo, E., Cerecedo, L.M., 2013. Effects of droplet collision phenomena on the development of pressure swirl sprays. Int. J. Multiph. Flow 56, 160-171. doi:10.1016/j.ijmultiphaseflow.2013.06.007

Sciences, P., Birch, D.M., Morrison, J.F., 2011. Similarity of the streamwise velocity component in very-rough-wall channel flow. J. Fluid Mech. 668, 174-201.

Tharakan, T.J., Mukhopadhyay, A., Datta, A., Jog, M. a., T. John Tharakan, Mukhopadhyay, A., Datta, A., Jog, M. a., 2013. Trends in Comprehensive Modeling of Spray Formation. Int. J. Spray Combust. Dyn. 5, 123-180. doi:10.1260/1756-8277.5.2.123

Tsai, S.C., Viers, B., 1990. Airblast atomization of viscous liquids. Fuel 69, 1412-1419. doi:10.1016/0016-2361(90)90123-8

Varga, C.M., Lasheras, J.C., Hopfinger, E.J., 2003. Initial breakup of a small-diameter liquid jet by a high-speed gas stream. J. Fluid Mech. 497, 405-434. doi:10.1017/S0022112003006724

Villermaux, E., 2004. Unifying ideas on mixing and atomization. New J. Phys. 6, 1-19. doi:10.1088/1367-2630/6/1/125 
Wigley, G., Goodwin, M., Pitcher, G., Blondel, D., 2004. Imaging and PDA analysis of a GDI spray in the near-nozzle region. Exp. Fluids 36, 565-574. doi:10.1007/s00348-003-0690-1

Xiangui, L., Tankin, R.S., 1987. Droplet Size Distribution: A Derivation of a Nukiyama-Tanasawa Type Distribution Function. Combust. Sci. Technol. 56, 6576. doi:10.1080/00102208708947081

Zheng, Q.P., Jasuja, A.K., Lefebvre, A.H., 1996. Influence of air and fuel flows on gas turbine sprays at high pressures. Symp. Combust. 26, 2757-2762. doi:10.1016/S0082-0784(96)80113-5 
Table 1. Summary of the fit of Eqs. (1)-(4) and (6) to the measurement data at $z=50 \mathrm{~mm}$.

682

\section{List of figures}

684 Fig. 1. The measurement configuration.

685 Fig. 2. Cross section of investigated atomizer.

686 Fig. 3. The PDA setup.

687 Fig. 4. Size-velocity correlations at $p_{g}=0.9$ bar and various axial distances: a) $10 \mathrm{~mm}$, b) $68815 \mathrm{~mm}$, c) $26.7 \mathrm{~mm}$, d) $50 \mathrm{~mm}$. All results were obtained at $\mathrm{r}=0 \mathrm{~mm}$.

689 Fig. 5. Size-velocity correlations at $\mathrm{z}=50 \mathrm{~mm}$ and various atomizing pressures a) $0.3 \mathrm{bar}$, 690 b) 0.9 bar, c) 2.1 bar, d) 3.1 bar. All results were obtained at $r=0 \mathrm{~mm}$.

691 Fig. 6. Radial profiles of TKE, MKE, axial and radial velocity profiles. All of these 692 characteristics are shown for liquid and gas phase in the spray and for: a) $z=10 \mathrm{~mm}, p_{g}$ $693=0.9$ bar, b) $z=15 \mathrm{~mm}, p_{g}=0.9$ bar, c) $z=27.6 \mathrm{~mm}, p_{g}=0.9$ bar, d) $z=50 \mathrm{~mm}, p_{g}=0.9$ 694 bar, e) $\left.\left.z=50 \mathrm{~mm}, p_{g}=0.3 \mathrm{bar}, \mathrm{f}\right) \mathrm{z}=50 \mathrm{~mm}, p_{g}=0.9 \mathrm{bar}, \mathrm{g}\right) \mathrm{z}=50 \mathrm{~mm}, p_{g}=2.1 \mathrm{bar}, \mathrm{h}$ ) $695 z=50 \mathrm{~mm}, p_{g}=3.1$ bar. Please note the different radial scale in a) and b).

696 Fig. 7. Size-velocity correlation at $z=50 \mathrm{~mm}$ and $r=0 \mathrm{~mm} \mathrm{a}) p_{g}=0.3$ bar and b) $p_{g}=$ $697 \quad 0.3,0.9,2.1$, and 3.1 bar.

698 Fig. 8. Radial $D_{32}$ distribution of the spray at various axial distances.

699 Fig. 9. Comparison of a) the calculated stable droplet sizes with b) measured $D_{32}$ at $700 \quad z=50 \mathrm{~mm}$.

701 Fig. 10. a) $I D_{32}$ of the spray at various axial distances and b) fitted estimations at $z=50$ 702 mm based on Eqs. (1)-(4) and (6).

703 Fig. 11. Average parameters of different PDFs at $z=50 \mathrm{~mm}$. a) $\Gamma$ and RR, b) NT, and c) 704 the averaged coefficient of determination of fits. 

Table 1.

\begin{tabular}{cccccc}
\hline Equation & Author(s) & Constant 1 & Constant 2 & $R^{2}$ & Comment \\
\hline$(1)$ & Lefebvre (1980) & 0.61 & 0.041 & 0.997 & \\
$(1)$ & Lefebvre (1980) & 0.66 & 0 & 0.986 & w/o Oh \\
$(2)$ & Rizk and Lefebvre (1984) & 0.48 & 0.15 & 0.0929 & with the original constants \\
$(2)$ & Rizk and Lefebvre (1984) & 0.47 & 0 & 0.926 & \\
$(3)$ & Varga et al. (2003) & $0.297 \mathrm{~m}^{0.5}$ & - & 0.991 & \\
$(4)$ & Lefebvre (1992) & 0.00082 & - & 0.702 & \\
$(6)$ & Park et al. (1996) & 2.04 & - & 0.0418 & \\
\hline
\end{tabular}


Fig. 1.

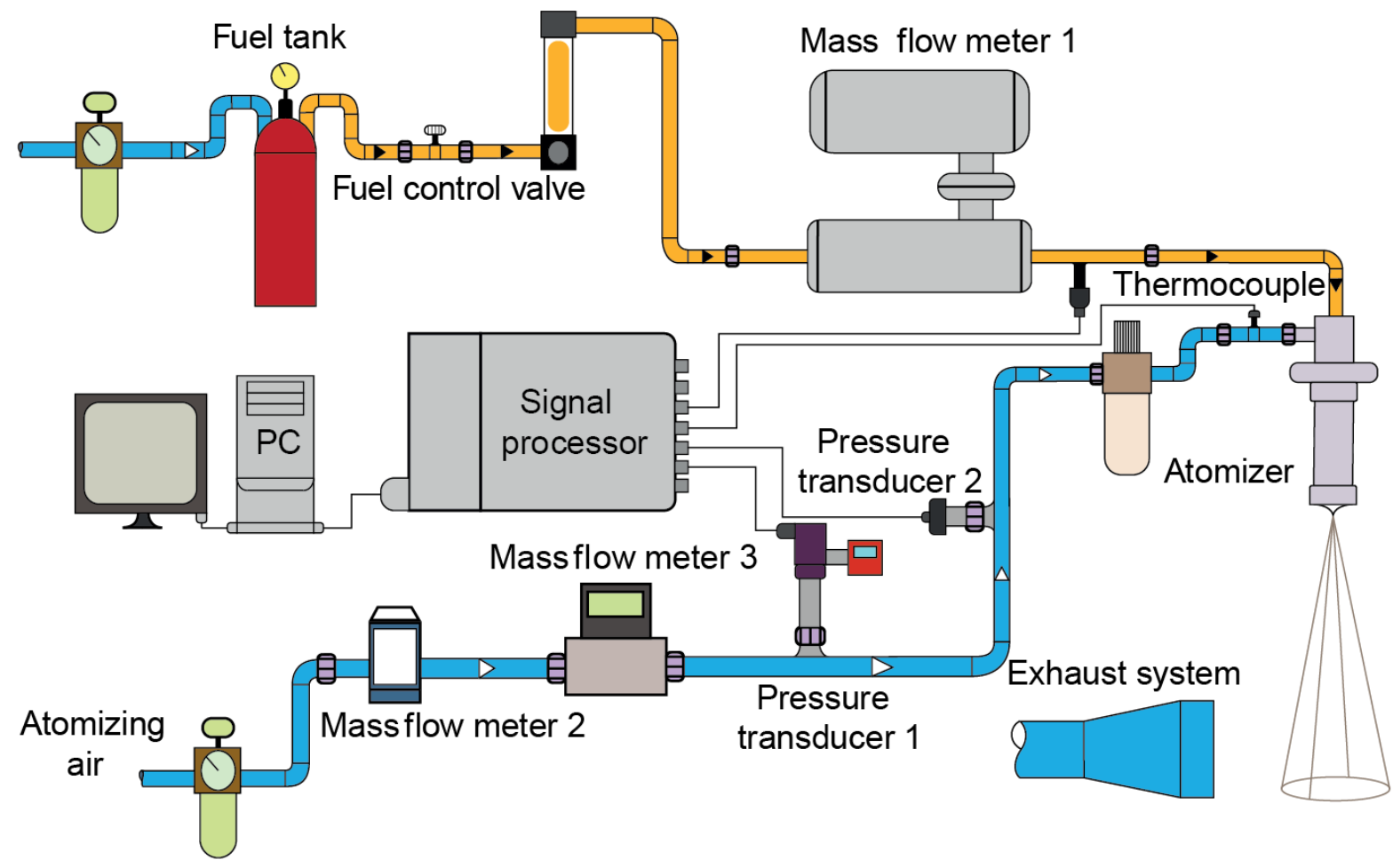

709

$710 \quad$ Fig. 2

711

712

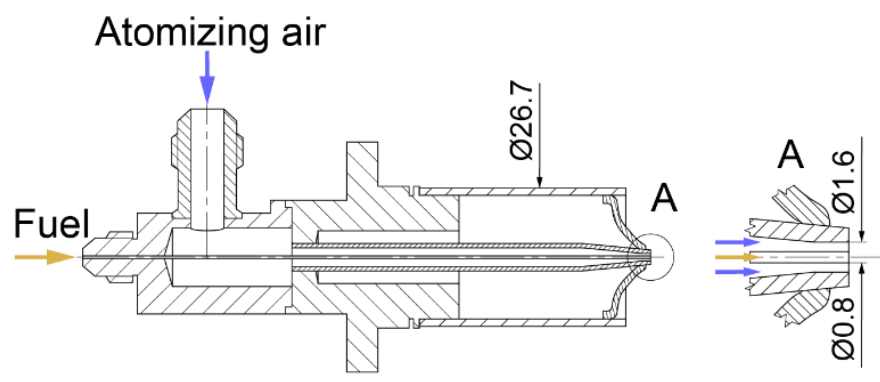


714

Fig. 3

715

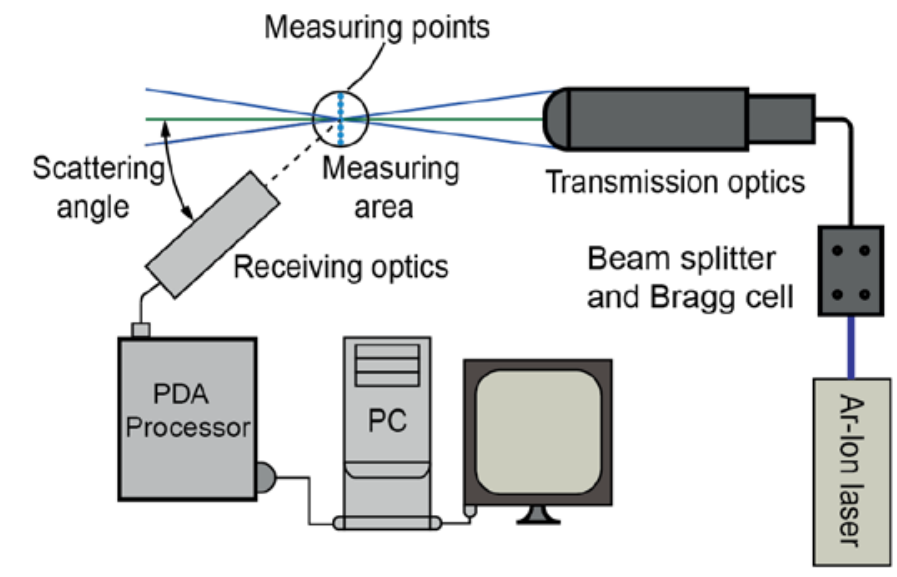

716

717

718 

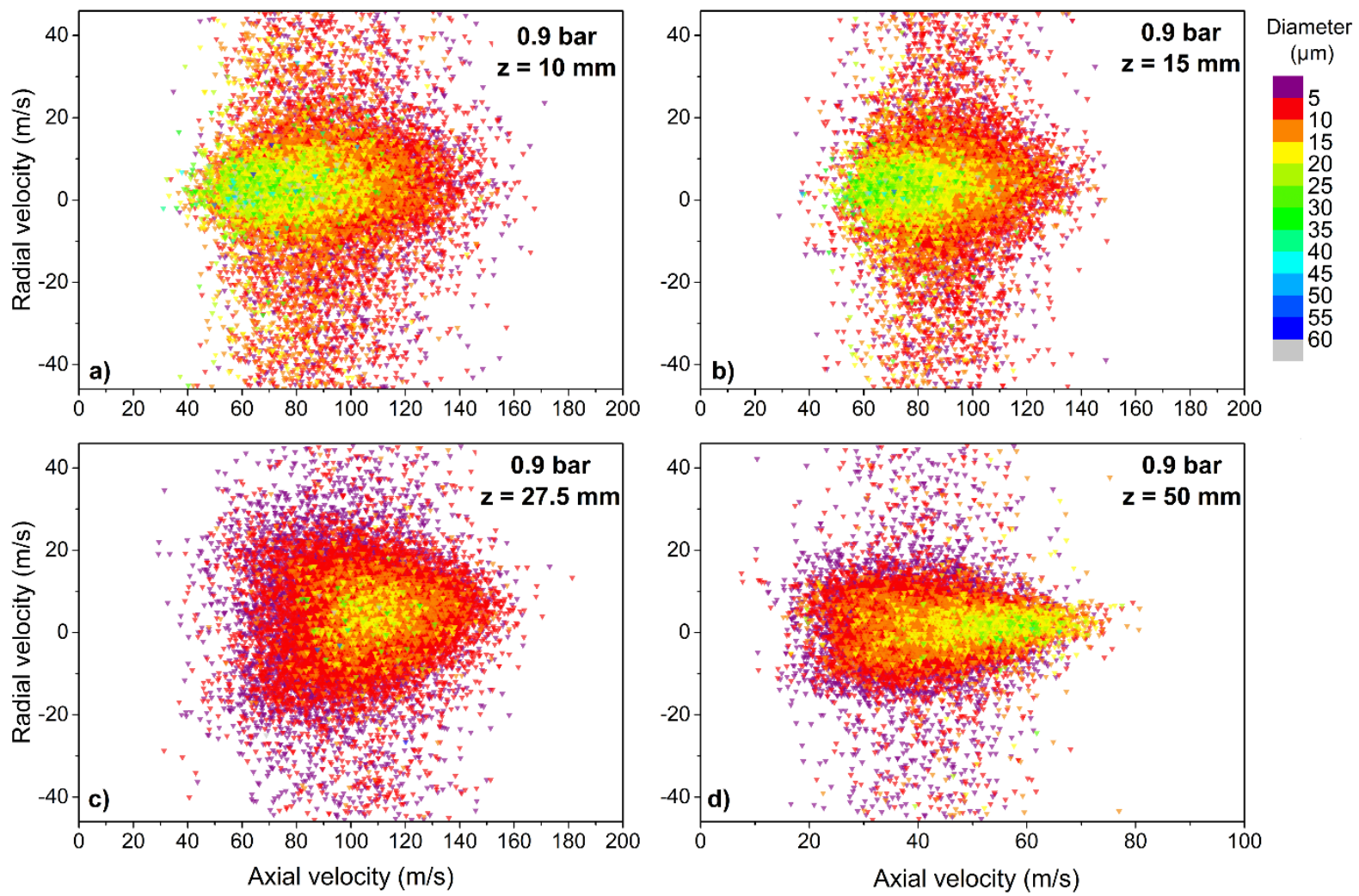

Fig. 5
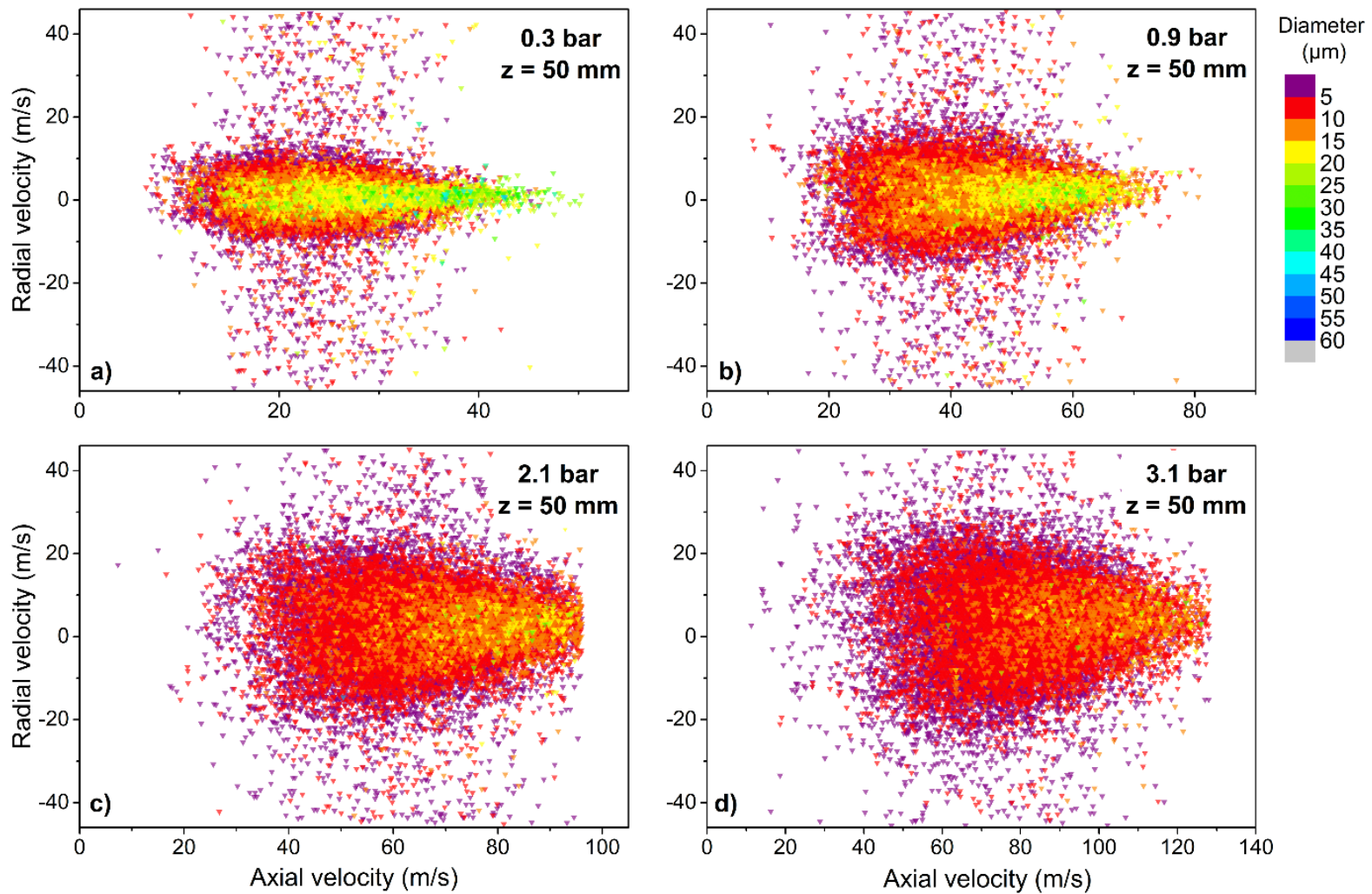


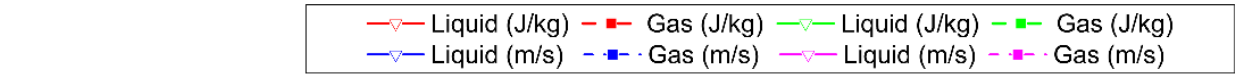
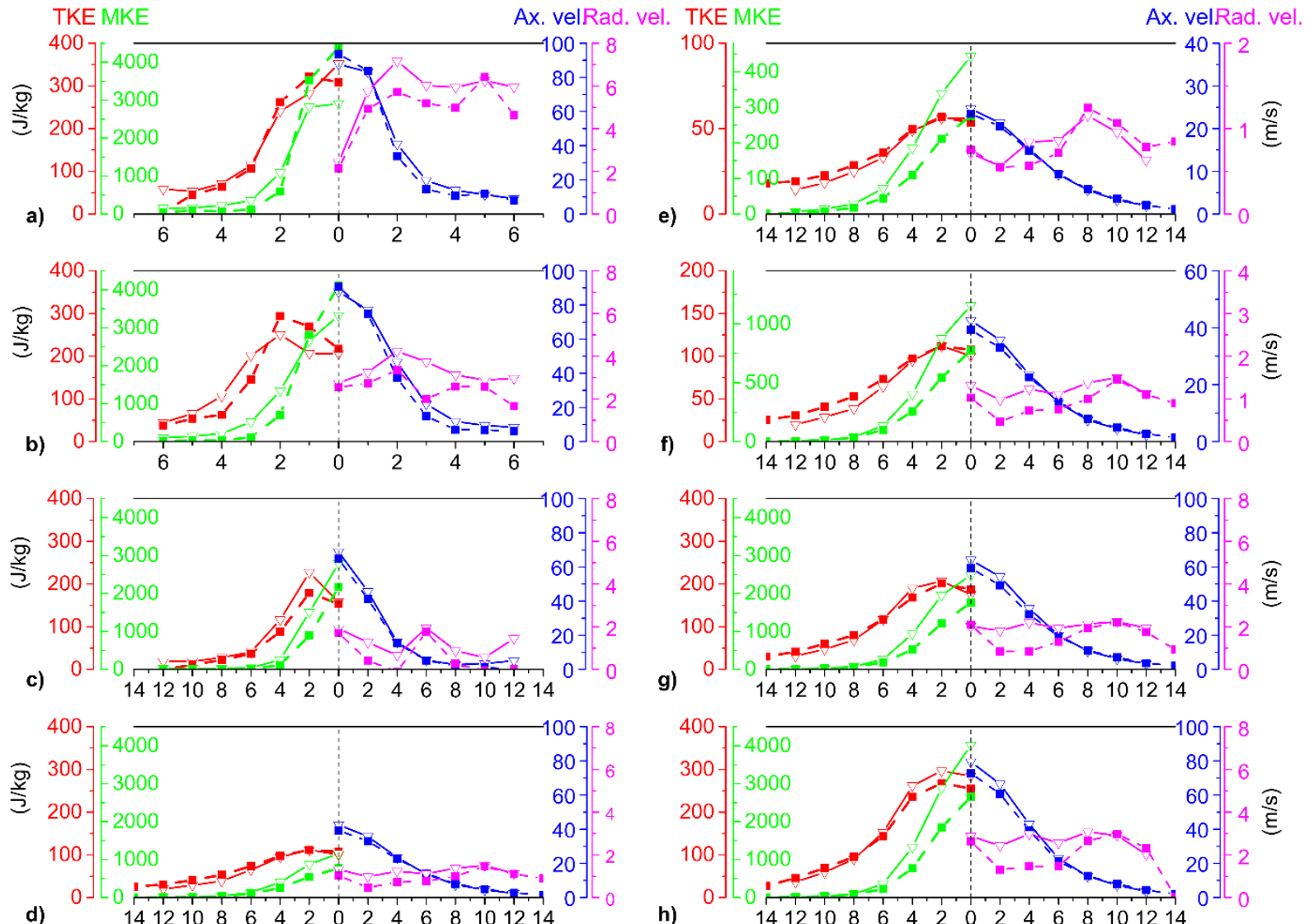

g)

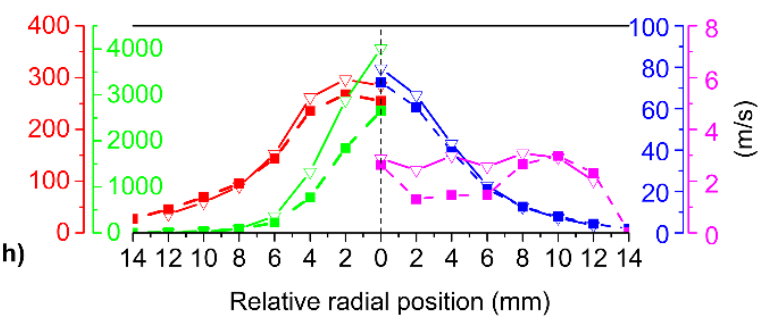


$728 \quad$ Fig. 7
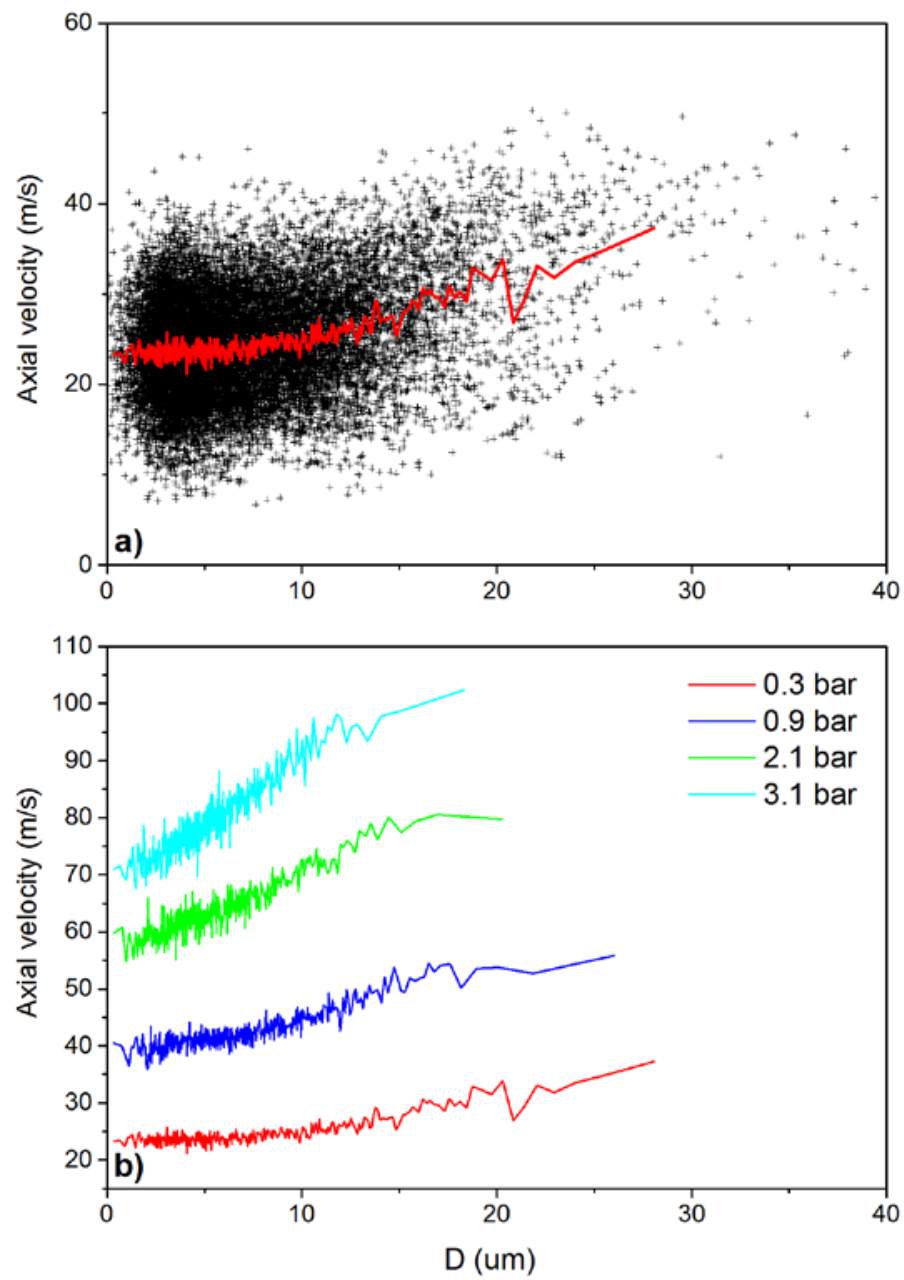

729

730 
Fig. 8

732

733
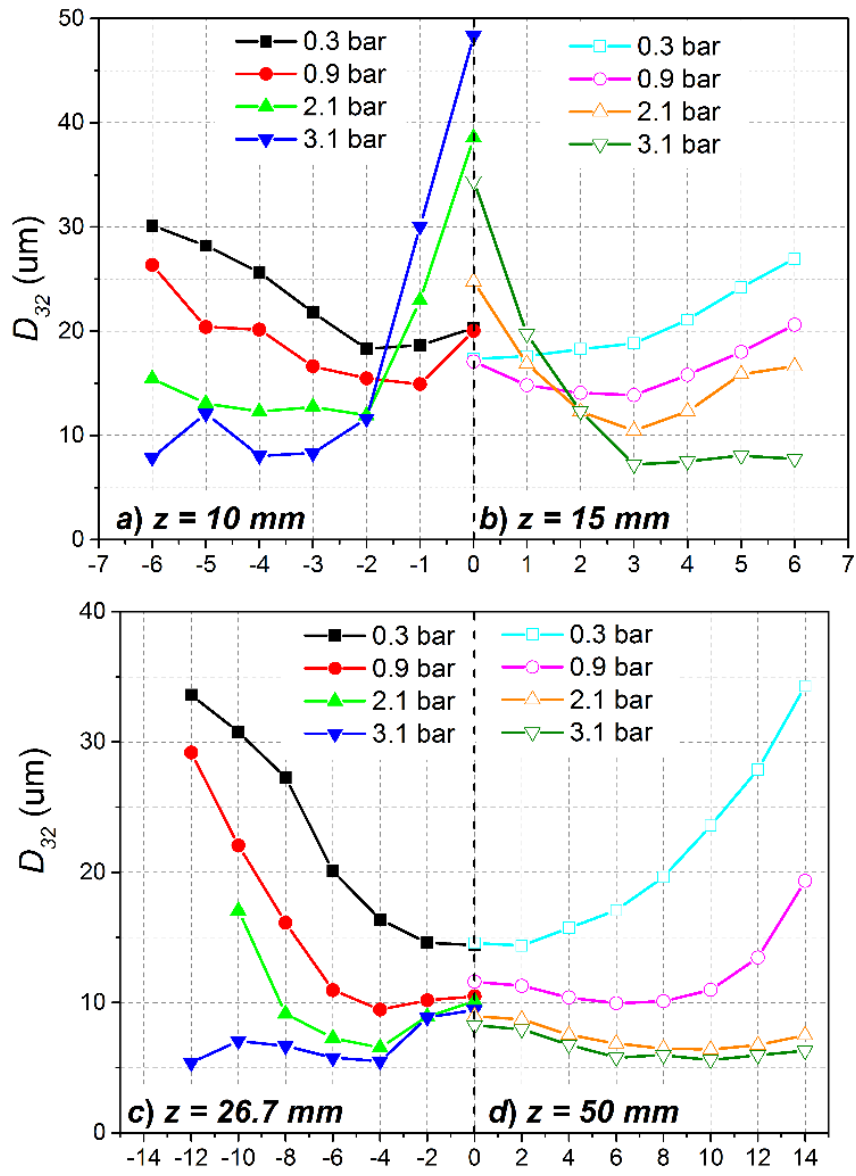

Radial distance $(\mathrm{mm})$ 
737

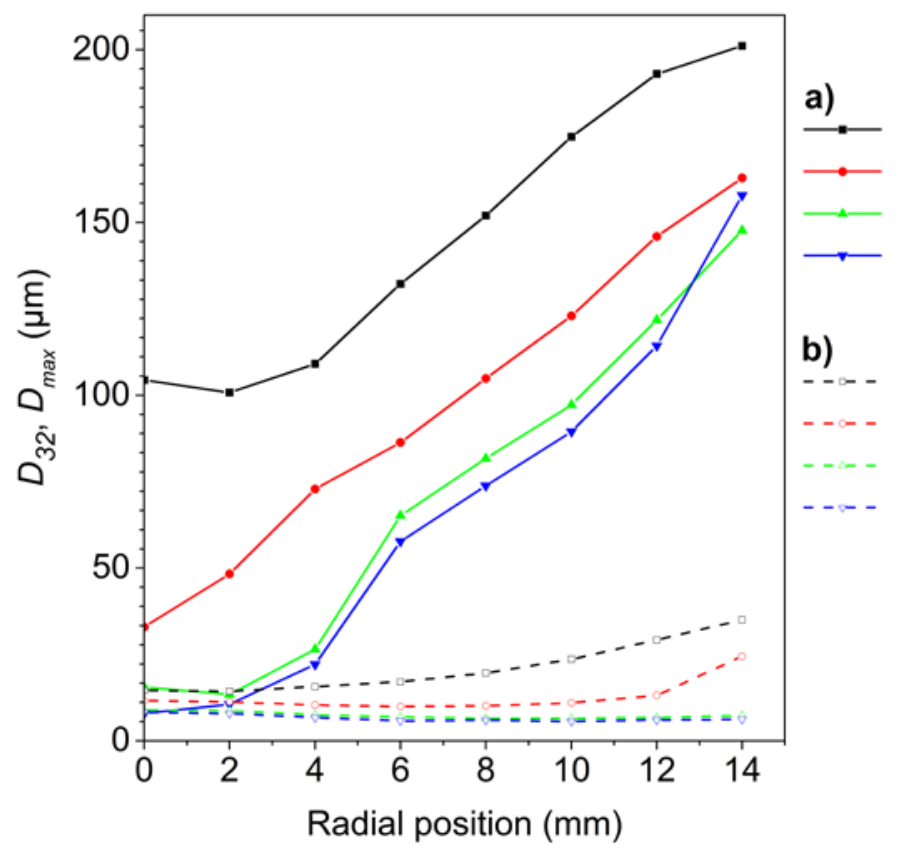

738

739 


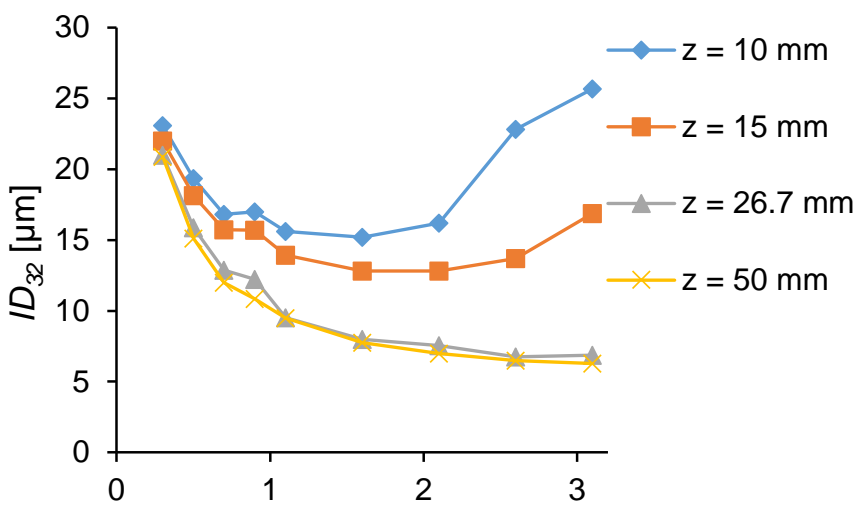

a)

$p_{g}$ [bar]

743

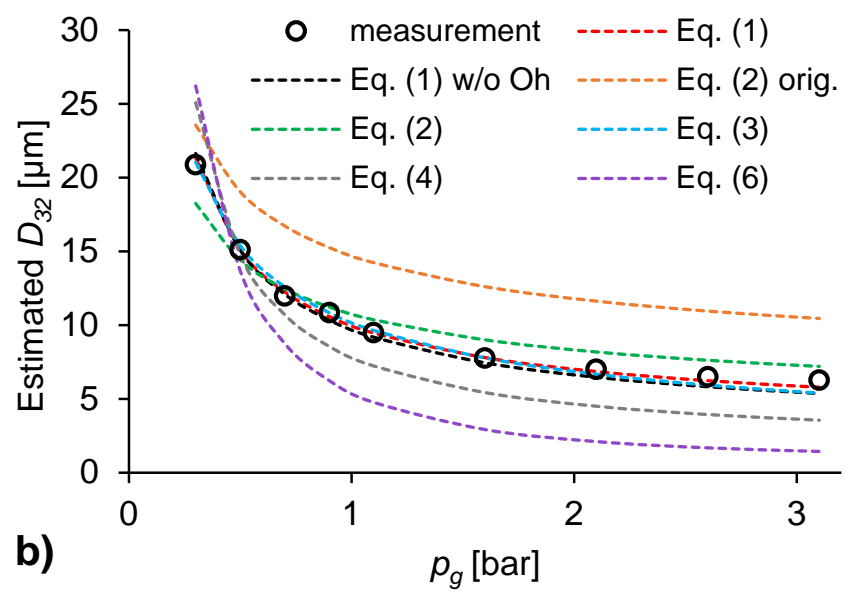


Fig. 11

747

748

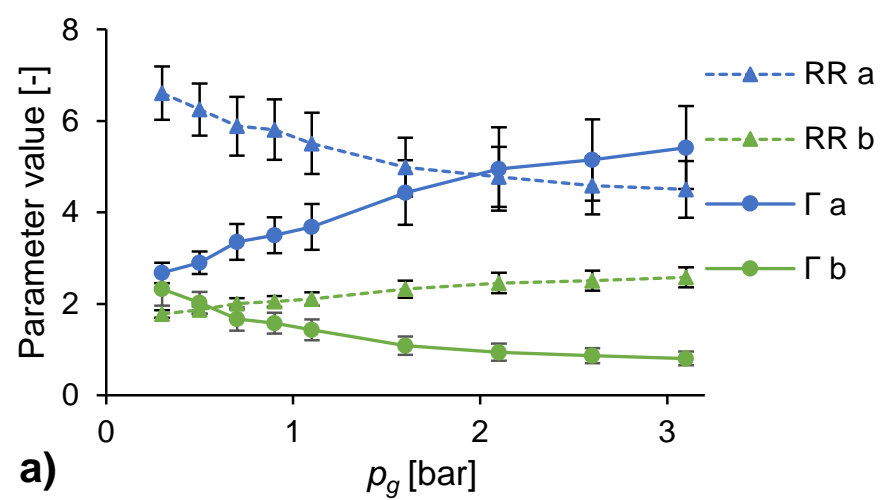

749

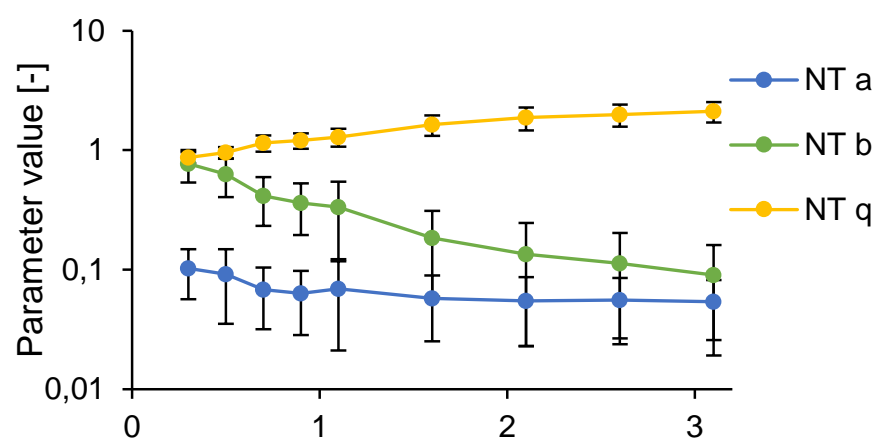

750

b)

$p_{g}$ [bar]

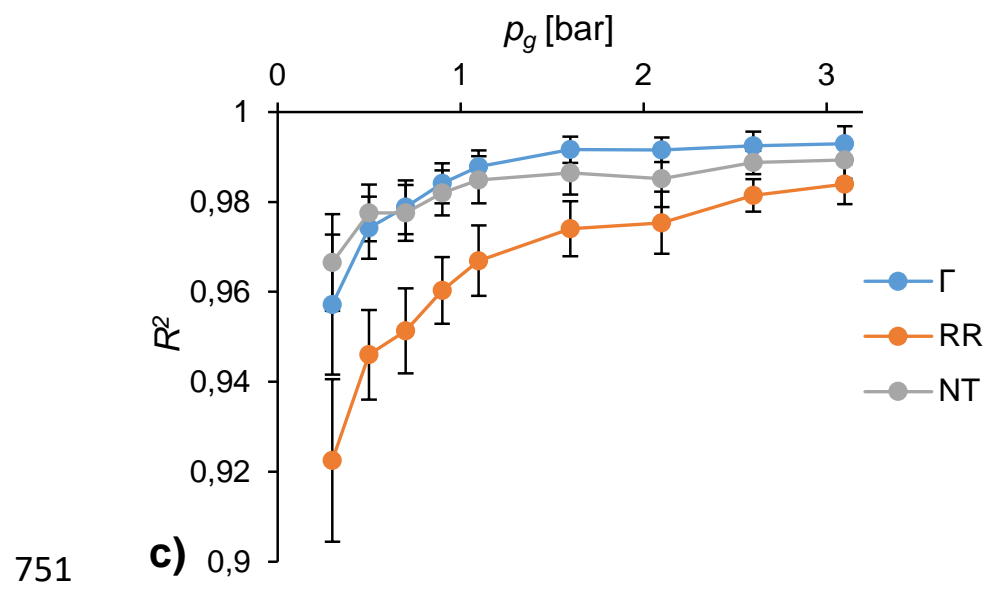

752 